\title{
Comparison of Docetaxel + Oxaliplatin + S-I vs Oxalipatin + S-I as Neoadjuvant Chemotherapy for Locally Advanced Gastric Cancer: A Propensity Score Matched Analysis
}

This article was published in the following Dove Press journal:

Cancer Management and Research

\author{
Xin Zhang ${ }^{1, *}$ \\ Hejing Huang ${ }^{2, *}$ \\ Ziran Wei ${ }^{1, *}$ \\ Zhenxin Zhu' \\ Dejun Yang' \\ Hongbing $\mathrm{Fu}^{\prime}$ \\ Jiapeng $\mathrm{Xu}^{\prime}$ \\ Zunqi Hu' \\ Yu Zhang' \\ Qing You' \\ Xin Huang' \\ Ronglin Yan' \\ Weimin Wang' \\ Qingping Cai (D) \\ 'Department of Gastrointestinal Surgery, \\ Changzheng Hospital, Second Military \\ Medical University, Shanghai, People's \\ Republic of China; ${ }^{2}$ Department of \\ Ultrasound, Changzheng Hospital, \\ Second Military Medical University, \\ Shanghai, People's Republic of China \\ *These authors contributed equally to \\ this work
}

Background: What is the optimal neoadjuvant chemotherapy (NAC) regimen for locally advanced gastric cancer (LAGC) remains debatable. The objective of this study was to compare the efficacy of docetaxel+oxaliplatin + S-1 (DOS) vs oxaliplatin + S-1 (SOX) as NAC for LAGC.

Methods: Data of 248 LAGC patients who received either DOS or SOX as NAC in our hospital between January 2010 and January 2018 were reviewed retrospectively. Propensity score matched (PSM) analysis was applied to minimize the selection bias in both groups. Prognostic factors were screened by univariate and multivariate Cox regression analyses.

Results: Of the 248 LAGC patients included, 180 patients were subjected to the PSM analysis. Patients in DOS group showed a better tumor response to NAC, higher radical resection rate and $\mathrm{R} 0$ resection rate than those in SOX group. The overall survival (OS) rate in DOS group was better than that in SOX group, although the overall incidence of Grade 3/4 NAC-related toxicity in DOS group was higher, as represented by leukopenia and neutropenia. Multivariate analysis revealed that the NAC regimen, cTNM stage and the R0 resection rate were independent prognostic factors. In addition, patients with TLND less than 16 population showed a worse OS rate. Subgroup analysis indicated that patients benefited from the addition of docetaxel regardless of the clinical $\mathrm{T}$ stage, but those with high clinical $\mathrm{N}$ stages (N2-3) did not.

Conclusion: DOS is a safe and feasible NAC regimen for LAGC, which is worth popularizing in clinical practice.

Keywords: locally advanced gastric cancer, neoadjuvant chemotherapy, radical gastrectomy, propensity score matched analysis, docetaxel

\section{Introduction}

Gastric cancer (GC) is one of the most common and lethal malignancies worldwide. ${ }^{1}$ Early detection and a timely radical surgical resection are so far the optimal treatment for GC. ${ }^{2}$ However, it is clinically difficult to diagnose an earlystage GC due to its commonly asymptomatic feature. ${ }^{3}$ A recent meta-analysis showed that endoscopic screening may reduce the risk of death from $\mathrm{GC}$ in Asian populations. ${ }^{4}$ However, most GC patients have been in their advanced stage at the time of diagnosis and lost the chance of radical surgery due to the low popularity and availability of endoscopic screening in China. ${ }^{5}$
Correspondence: Qingping Cai; Ronglin Yan

Tel +86-2I-8I 88560I; +86-2I-8I885603 Fax +86-2I-8I886000

Email caiqingping@smmu.edu.cn; yanronglin@smmu.edu.cn 
The current therapeutic principle for locally advanced gastric cancer (LAGC) is multidisciplinary with surgical procedures as the core. ${ }^{6}$ For potentially resectable cases, neoadjuvant chemotherapy (NAC) may help decrease the tumor stage and eliminate occult micrometastasis so as to improve the $\mathrm{R} 0$ resection rate. ${ }^{7,8}$ In addition, part of the initially unresectable LAGC patients can be successfully converted to resectable cases by NAC and then undergo curative surgery. ${ }^{9}$ In the past decades, several clinical trials have been conducted to assess the efficacy and safety of NAC for LAGC. ${ }^{10,11}$

The MAGIC trial published in 2006 is regarded as the landmark to uncover the effectiveness of NAC regimens for LAGC, saying that perioperative chemotherapy with epirubicin, cisplatin and fluorouracil (ECF) could improve overall survival (OS) vs surgery alone in patients with non-metastatic stage II and higher GC. ${ }^{12}$ Also, another multicenter randomized controlled trial (RCT) reported that NAC with cisplatin and 5-FU could increase the survival of patients with resectable gastroesophageal adenocarcinoma, as compared with surgery alone. ${ }^{13}$ Furthermore, the FLOT4-AIO trial demonstrated that the combination of docetaxel, oxaliplatin, leucovorin and 5-FU (FLOT) was superior to the ECF regimen as NAC for resectable advanced GC. ${ }^{14}$ However, the inconvenience of continuous intravenous (IV) 5-FU infusion limits the use of this regimen worldwide as a popular chemotherapeutic regimen. Therefore, the consensus for the optimal NAC regimen for GC is still far from being reached. ${ }^{15}$

Two cytotoxic drugs are preferred for advanced GC and three-drug regimens are reserved for medically fit patients according to the NCCN guidelines. ${ }^{16}$ Accordingly, combination of S-1 and cisplatin/oxaliplatin has long been used as the standard chemotherapy regimen under adjuvant, neoadjuvant and palliative settings for GC in East Asia. ${ }^{17-19}$ However, peritoneal metastasis remains highly prevalent in advanced GC even under S-1 and oxaliplatin therapy. ${ }^{20}$ Intravenous administration of docetaxel can effectively penetrate ascites; thus, a NAC regimen involving docetaxel would be helpful for eliminating peritoneal metastasis. ${ }^{21}$ Therefore, we designed this study to investigate the efficacy and safety of docetaxel, oxaliplatin and S-1 (DOS) vs oxaliplatin and S-1 (SOX) as NAC for potentially resectable LAGC.

\section{Methods}

\section{Study Design}

This retrospective cohort study was designed to compare the efficacy and safety of DOS vs SOX as a NAC regimen for patients with potentially resectable locally advanced GC (LAGC). Clinical data used in this study were obtained from the medical records of both inpatients and outpatients in the Department of gastrointestinal surgery, Changzheng Hospital affiliated to the Second Military Medical University (Shanghai, China). In addition, patients or relatives were contacted via telephone or Wechat for cases that lacked information. All participants included in this study signed written informed consent for their medical information to be used for uncommercial scientific research. Propensity scorematched (PSM) analysis was used to match the two groups on a 1:1 basis. This study was conducted in accordance with the Declaration of Helsinki and approved by the ethics committee of Changzheng Hospital, Second Military Medical University.

\section{Inclusion and Exclusion Criteria}

Both male and female patients aged 18-75 years with histologically confirmed gastric adenocarcinoma between January 2010 and January 2018 were eligible for inclusion. The eligibility criteria were as follows: 1) clinical staging as T2-4bN0-3M0 based on the 7th American Joint Committee on Cancer (AJCC) staging system; 2) receiving NAC of either DOS or SOX regimen; and 3) Eastern Cooperative Oncology Group (ECOG) score 0-1 point.

Patients were excluded from the study if they met any of the following criteria: 1) contemporaneous existence or a previous history of other malignancies; 2) gastric stump cancer; 3) received preoperative radiotherapy; 4) existence of distant metastasis including retroperitoneal lymph node, left supraclavicular lymph node, liver, lung or bone metastasis; 5) peritoneal dissemination by laparoscopic screening; and 6) uncontrolled systemic diseases.

\section{Preoperative Evaluation and Staging}

All patients underwent abdominal and pelvic contrastenhanced computed tomography (CT) and/or endoscopic ultrasonography to acquire preoperative staging. For patients stage $\mathrm{T} 3 \mathrm{~N} 1$ or above, or who were suspected as having peritoneal metastasis, laparoscopic exploration was routinely performed to further accurate staging unless the patient was medically unfit.

\section{Neoadjuvant Chemotherapy}

DOS: Docetaxel at $75 \mathrm{mg} / \mathrm{m}^{2}$ and oxaliplatin at $130 \mathrm{mg} / \mathrm{m}^{2}$ were administered IV on day 1 , and S-1 was administered orally at $80 \mathrm{mg} / \mathrm{d} / \mathrm{m}^{2}$ (body surface area $<1.25 \mathrm{~m}^{2}$ ), $100 \mathrm{mg} / \mathrm{d} / \mathrm{m}^{2}\left(1.25 \mathrm{~m}^{2} \leq\right.$ body surface area $\left.<1.5 \mathrm{~m}^{2}\right)$, and 
$120 \mathrm{mg} / \mathrm{d} / \mathrm{m}^{2}$ (body surface area $\geq 1.5 \mathrm{~m}^{2}$ ) respectively on day 1-14 of a 21-day cycle.

SOX: Oxaliplatin at $130 \mathrm{mg} / \mathrm{m}^{2}$ was administered IV on day 1 , and S-1 was administered orally at $80 \mathrm{mg} / \mathrm{d} / \mathrm{m}^{2}$ (body surface area $\left.<1.25 \mathrm{~m}^{2}\right), 100 \mathrm{mg} / \mathrm{d} / \mathrm{m}^{2}\left(1.25 \mathrm{~m}^{2} \leq\right.$ body surface area $<1.5 \mathrm{~m}^{2}$ ), and $120 \mathrm{mg} / \mathrm{d} / \mathrm{m}^{2}$ (body surface area $\geq 1.5 \mathrm{~m}^{2}$ ) respectively on day $1-14$ of a 21 -day cycle.

NAC was given as soon as the diagnosis was established and the contraindications for chemotherapy were excluded. For patients who underwent laparoscopic exploration, NAC would be given within 2 days after surgery.

\section{Response and Toxicity Evaluation}

Treatment response of each patient was assessed using an abdominal and pelvic contrast-enhanced $\mathrm{CT}$ by a professional gastrointestinal radiologist based on the Response Evaluation Criteria in Solid Tumors (RECIST) guideline 1.1. ${ }^{22}$ NAC-related toxicity was evaluated according to the National Cancer Institute Common Toxicity Criteria version $3.0,{ }^{23}$ and the data indicating the most severe toxicity for each patient within the whole neoadjuvant chemotherapy course were used in the analysis.

\section{Surgical Treatment}

After three cycles of NAC, tumor resectability was reassessed by a multidisciplinary team (MDT). All patients identified as resectable by MDT received curative-intent surgery, including radical gastrectomy with standardized D2 lymphnode dissection. Surgery was scheduled for 3 weeks after the last dose of preoperative chemotherapy. Unresectable cases, identified by either the MDT or reevaluation of the surgeon during operation, would continue with NAC by using either the initial or alternative regimen and were defined as "unresectable" regardless of the subsequent outcome.

\section{Postoperative Treatment and Follow-Up Observation}

Patients who received $\mathrm{R} 0$ resection were given priority to adjuvant chemotherapy with the SOX regimen for three cycles in both groups. S-1 monotherapy was reserved for those who were unable to tolerate two-drug therapy. All patients were followed up regularly by clinic visits, telephone, or Wechat. Serum tumor biomarkers including carcinoembryonic antigen (CEA), CA19-9, CA125, and AFP were tested every 3 months for the first 2 years after surgery, and every 6 months thereafter. Chest X-ray, abdominal and pelvic contrast-enhanced CT were performed every 6 months for the first 2 years, and annually thereafter. Gastrointestinal endoscopy was conducted annually.

\section{Statistical Analysis}

PSM was used to minimize the selection bias from a retrospective study on the assessed outcomes between DOS and SOX groups. The PSM was estimated by using a nonparsimonious multivariable logistic-regression model, with the NAC group as the dependent variable and all the baseline characteristics outlined in Table 1 as covariates. Matching was performed with a caliper of 0.05 .

Student's $t$-test and chi-square test were used to compare continuous and categorical data respectively between the two groups. Kaplan-Meier analysis with Log rank testing was used for OS. Associated factors predictive of OS were assessed by both univariate and multivariate Cox proportional regression analyses. Values of $p<0.05$ were considered statistically significant. All statistical analyses were performed by SPSS program (PASW Statistics for Windows, Version 22.0; Inc, Chicago, IL) and GraphPad Software (GraphPad Prism 5.0; La Jolla, CA, USA).

\section{Results}

\section{Patient Characteristics}

A total of 568 patients with histologically proven LAGC received NAC in our department between January 2010 and January 2018. After excluding 320 patients for various reasons, the remaining 248 patients were included in the initial statistical analysis, including 92 in DOS group and 156 in SOX group. Their baseline demographics and clinical characteristics are shown in Table 1. The two groups were not balanced with regard to age and clinical $\mathrm{T}$ stage variates, and the disparities were resolved after PSM manipulation (Table 1). The specific flowchart of the patients' enrollment is shown in Figure 1.

\section{Response to NAC}

In the unmatched study, the overall tumor response to NAC was not statistically significant between the two groups, but an obvious trend was seen that the DOS group showed a better tumor response than the SOX group $(\mathrm{p}=0.051$, Table 2). Patients in DOS group achieved a higher response rate $(R R, p=0.033)$ and a disease control rate (DCR, $\mathrm{p}=0.033)$. The result of PSM analysis showed that NAC with DOS was superior to SOX with respect to tumor response ( $\mathrm{p}=0.005$, Table 2). Complete response (CR) was 
Table I The Baseline Demographics and Clinical Characteristics

\begin{tabular}{|c|c|c|c|c|c|c|}
\hline \multirow[t]{2}{*}{ Variable } & \multicolumn{3}{|c|}{ Before PSM } & \multicolumn{3}{|l|}{ After PSM } \\
\hline & $\begin{array}{l}\text { DOS } \\
n=92(\%)\end{array}$ & $\begin{array}{l}\text { sox } \\
n=156 \text { (\%) }\end{array}$ & $\mathbf{P}$ & DOS n=90 (\%) & sox $n=90(\%)$ & $\mathbf{P}$ \\
\hline $\begin{array}{l}\text { Gender } \\
\text { Male } \\
\text { Female }\end{array}$ & $\begin{array}{l}68(73.9) \\
24(26.1)\end{array}$ & $\begin{array}{l}\text { II }(73.7) \\
4 I(26.3)\end{array}$ & 0.973 & $\begin{array}{l}66(73.3) \\
24(26.7)\end{array}$ & $\begin{array}{l}58(64.4) \\
32(35.6)\end{array}$ & 0.198 \\
\hline $\begin{array}{l}\text { Age (years) } \\
<-40 \\
41-59 \\
60-75\end{array}$ & $\begin{array}{l}17(18.5) \\
44(47.8) \\
31(33.7)\end{array}$ & $\begin{array}{l}19(12.2) \\
57(36.5) \\
80(51.3)\end{array}$ & 0.025 & $\begin{array}{l}16(17.8) \\
43(47.8) \\
31(34.4)\end{array}$ & $\begin{array}{l}17(18.9) \\
40(44.4) \\
33(36.7)\end{array}$ & 0.904 \\
\hline $\begin{array}{l}\text { Tumor location } \\
\text { Upper } \\
\text { Middle } \\
\text { Lower }\end{array}$ & $\begin{array}{l}25(27.2) \\
33(35.9) \\
34(37.0)\end{array}$ & $\begin{array}{l}31 \text { (19.9) } \\
58(37.2) \\
67(42.9)\end{array}$ & 0.386 & $\begin{array}{l}25(27.8) \\
33(36.7) \\
32(35.6)\end{array}$ & $\begin{array}{l}22(24.4) \\
38(42.2) \\
30(33.3)\end{array}$ & 0.738 \\
\hline $\begin{array}{l}\text { Differentiation } \\
\text { Well } \\
\text { Moderately } \\
\text { Poorly }\end{array}$ & $\begin{array}{l}10(10.9) \\
26(28.3) \\
56(60.9)\end{array}$ & $\begin{array}{l}17(10.9) \\
45(28.8) \\
94(60.3)\end{array}$ & 0.995 & $\begin{array}{l}10(11.1) \\
26(28.9) \\
54(60.0)\end{array}$ & $\begin{array}{l}9(10.0) \\
24(26.7) \\
57(63.3)\end{array}$ & 0.899 \\
\hline $\begin{array}{l}\text { cT staging } \\
\text { cT2 } \\
\text { cT3 } \\
\text { cT4a } \\
\text { cT4b }\end{array}$ & $\begin{array}{l}12(13.0) \\
30(32.6) \\
34(37.0) \\
16(17.4)\end{array}$ & $\begin{array}{l}44(28.2) \\
58(37.2) \\
37(23.7) \\
17(10.9)\end{array}$ & 0.009 & $\begin{array}{l}12(13.3) \\
30(33.3) \\
32(35.6) \\
16(17.8)\end{array}$ & $\begin{array}{l}19(21.1) \\
26(28.9) \\
30(33.3) \\
15(16.7)\end{array}$ & 0.580 \\
\hline $\begin{array}{l}\text { cN staging } \\
\text { cN0 } \\
\text { cNI } \\
\text { cN2 } \\
\text { cN3 }\end{array}$ & $\begin{array}{l}18(19.6) \\
28(30.4) \\
22(23.9) \\
24(26.1)\end{array}$ & $\begin{array}{l}41(26.3) \\
64(41.0) \\
24(15.4) \\
27(17.3)\end{array}$ & 0.063 & $\begin{array}{l}18(20.0) \\
28(31.1) \\
21(23.3) \\
23(25.6)\end{array}$ & $\begin{array}{l}20(22.2) \\
28(31.1) \\
18(20.0) \\
24(26.7)\end{array}$ & 0.949 \\
\hline $\begin{array}{l}\text { Lauren classification } \\
\text { Intestinal } \\
\text { Diffuse } \\
\text { Mixed }\end{array}$ & $\begin{array}{l}36(39.1) \\
35(38.0) \\
21(22.8)\end{array}$ & $\begin{array}{l}69(44.2) \\
58(37.2) \\
29(18.6)\end{array}$ & 0.643 & $\begin{array}{l}36(40.0) \\
34(37.8) \\
20(22.2)\end{array}$ & $\begin{array}{l}36(40.0) \\
35(38.9) \\
19(21.1)\end{array}$ & 0.980 \\
\hline
\end{tabular}

Note: Bold formatting was used when $\mathrm{p}$ value was less than 0.05 .

Abbreviations: PSM, propensity score matching; DOS, docetaxel, oxaliplatin and S-I; SOX, oxaliplatin and S-I.

achieved in 7 (7.8\%) and $2(2.2 \%)$ patients in DOS and SOX groups, respectively. The RR and DCR was $80.0 \%$ and $96.7 \%$ in DOS group respectively vs $60.0 \%$ and $84.4 \%$ in SOX group.

\section{NAC-Related Adverse Events}

As shown in Table 3, the overall incidence of Grade 3/4 NACrelated adverse events was higher in DOS group (55.4\%) than that in SOX group (34.6\%) before PSM ( $\mathrm{p}=0.001)$, and the difference was also significant after PSM $(\mathrm{p}=0.011)$. However, there was no NAC-related death in either group. Three patients in DOS group and one patient in SOX group dropped out of the NAC due to intolerable toxicity, showing no statistically significant difference between the two groups. The most common Grade 3/4 adverse events were leukopenia and neutropenia in both groups. Patients in DOS group experienced a higher incidence of leukopenia $(27.8 \%$ vs 12.2 , $\mathrm{p}=0.009)$ and neutropenia ( $38.9 \%$ vs $16.7 \%, \mathrm{p}=0.001)$ as compared with SOX group.

\section{The Surgical Resection Rate}

In the unmatched study, 77 patients in DOS group underwent radical surgery, of whom 74 patients received R0 resection; of the 126 patients in SOX group who 


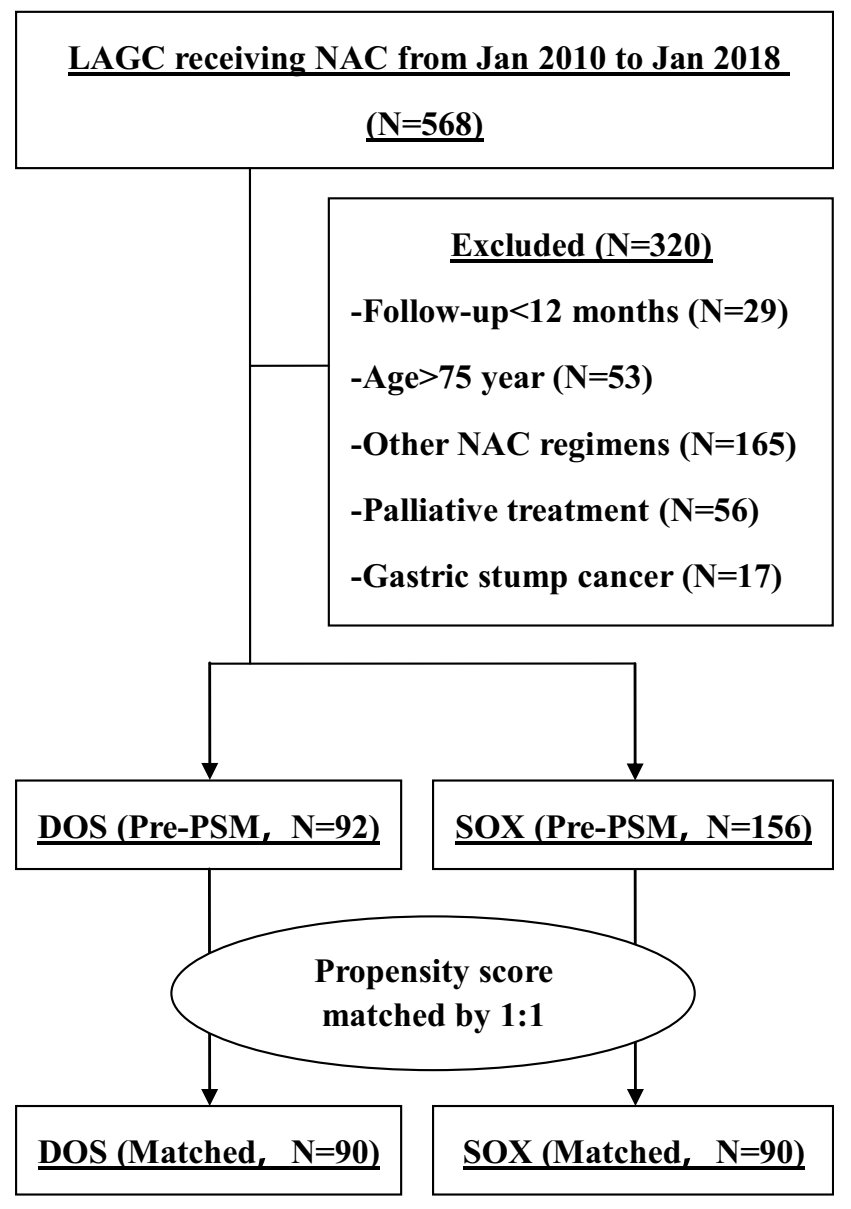

Figure I Flowchart showing the patient enrollment.

Abbreviations: LAGC, locally advanced gastric cancer; PSM, propensity score matching; NAC, neoadjuvant chemotherapy; DOS, docetaxel, oxaliplatin and S-I; SOX, oxaliplatin and S-I.

underwent radical surgery, 121 patients received $\mathrm{R} 0$ resection. No perceptible differences were observed in terms of the radical resection rate, $\mathrm{R} 0$ resection rate and residual tumor classification between the two groups (Table 4). In the PSM analysis, 75 patients in DOS group underwent radical surgery, of whom 72 patients received $\mathrm{R} 0$ resection; of the 62 patients in SOX group underwent radical surgery, 58 patients received $\mathrm{R} 0$ resection. Both the radical resection rate and $\mathrm{R} 0$ resection rate in patients of DOS group were significantly higher than those in SOX group $(83.3 \%$ vs $68.9 \%, \mathrm{p}=0.023 ; 80.0 \%$ vs $64.4 \%, \mathrm{p}=0.020)$ (Table 4).

\section{Surgical and Postoperative Outcomes}

Among the 203 patients who underwent radical surgery, no perioperative death occurred in either group. The incidence of perioperative complications and the number of total lymph nodes dissected (TLND) were both comparable between the two groups (Table 5). The ypT stage and $y \mathrm{pN}$ stage were both similar in the unmatched analysis. However, the PSM analysis showed that the ypT stage in patients of DOS group was significantly lower than that of SOX group $(p=0.043)$, while there was no significant difference in the ypN stage $(\mathrm{p}=0.143)$.

\section{Survival Analysis}

The unmatched analysis showed that the median length of follow-up was 57 (range 5-105) months. The median survival time for patients in DOS group and SOX group was 61 months and 46 months respectively, showing no statistically significant difference between the two groups $(p=0.206)$ (Figure 2A). The 3-year survival rates in DOS group and SOX group was $64.0 \%$ and $60.7 \%$, respectively $(\mathrm{p}=0.612)$; the 5-year survival rate was $50.9 \%$ and $38.8 \%$, respectively $(\mathrm{p}=0.066)$. After PSM, the median length of follow-up was 58 months (range 5-105 months). KaplanMeier analysis revealed that DOS arm yielded better OS

Table 2 Response to NAC According to RECIST Guideline

\begin{tabular}{|c|c|c|c|c|c|c|}
\hline \multirow[t]{3}{*}{ Variable } & \multicolumn{3}{|c|}{ Before PSM } & \multicolumn{3}{|c|}{ After PSM } \\
\hline & \multirow{2}{*}{$\begin{array}{l}\text { DOS } \\
n=92(\%)\end{array}$} & \multirow{2}{*}{$\begin{array}{l}\text { sox } \\
n=156(\%)\end{array}$} & \multirow[t]{2}{*}{$\mathbf{P}$} & \multirow{2}{*}{$\begin{array}{l}\text { DOS } \\
n=90(\%)\end{array}$} & \multirow{2}{*}{$\begin{array}{l}\text { SOX } \\
n=90 \text { (\%) }\end{array}$} & \multirow[t]{2}{*}{$\mathbf{P}$} \\
\hline & & & & & & \\
\hline Response to NAC & & & 0.051 & & & 0.005 \\
\hline CR & $7(7.6)$ & $5(3.2)$ & & $7(7.8)$ & $2(2.2)$ & \\
\hline PR & $67(72.8)$ & 101 (64.7) & & $65(72.2)$ & $52(57.8)$ & \\
\hline SD & $15(16.3)$ & $33(2 \mid .2)$ & & $15(16.7)$ & $22(24.4)$ & \\
\hline PD & $3(3.3)$ & $17(10.9)$ & & $3(3.3)$ & $14(15.6)$ & \\
\hline $\mathrm{RR}(\mathrm{CR}+\mathrm{PR})$ & $74(80.4)$ & $106(67.9)$ & 0.033 & $72(80.0)$ & $54(60.0)$ & 0.003 \\
\hline $\mathrm{DCR}(\mathrm{CR}+\mathrm{PR}+\mathrm{SD})$ & $89(96.7)$ & $139(89.1)$ & 0.033 & $87(96.7)$ & $76(84.4)$ & 0.005 \\
\hline
\end{tabular}

Note: Bold formatting was used when $p$ value was less than 0.05 .

Abbreviations: PSM, propensity score matching; DOS, docetaxel, oxaliplatin and S-I; SOX, oxaliplatin and S-I; CR, complete response; PR, partial response; SD, stable disease; PD, progression disease; RR, response rate; DCR, disease control rate. 
Table 3 Grade 3/4 NAC-Related Adverse Events

\begin{tabular}{|c|c|c|c|c|c|c|}
\hline \multirow[t]{2}{*}{ Event } & \multicolumn{3}{|c|}{ Before PSM } & \multicolumn{3}{|c|}{ After PSM } \\
\hline & $\begin{array}{l}\text { DOS } \\
n=92(\%)\end{array}$ & $\begin{array}{l}\text { sox } \\
n=156 \text { (\%) }\end{array}$ & $\mathbf{P}$ & $\begin{array}{l}\text { DOS } \\
n=90 \text { (\%) }\end{array}$ & $\begin{array}{l}\text { sox } \\
n=90 \text { (\%) }\end{array}$ & $\mathbf{P}$ \\
\hline Overall toxicity & $51(55.4)$ & $54(34.6)$ & 0.001 & $51(56.7)$ & $34(37.8)$ & 0.011 \\
\hline Related death & $0(0)$ & $0(0)$ & NA & $0(0)$ & $0(0)$ & NA \\
\hline Aborting of NAC & $3(3.3)$ & I $(0.6)$ & 0.114 & $3(3.3)$ & I (I.I) & 0.312 \\
\hline Leukopenia & $25(27.2)$ & $18(11.5)$ & 0.002 & $25(27.8)$ & II (I2.2) & 0.009 \\
\hline Neutropenia & $35(38.0)$ & $27(17.3)$ & $<0.001$ & $35(38.9)$ & $15(16.7)$ & 0.001 \\
\hline Thrombocytopenia & II (I2.0) & $10(6.4)$ & 0.130 & $10(1 \mathrm{I} . \mathrm{I})$ & $9(10.0)$ & 0.808 \\
\hline Anorexia & $9(9.8)$ & $7(4.5)$ & 0.101 & $9(10.0)$ & $5(5.6)$ & 0.266 \\
\hline Vomiting & $4(4.3)$ & $4(2.6)$ & 0.442 & $4(4.4)$ & $2(2.2)$ & 0.406 \\
\hline Neurotoxicity & $6(6.5)$ & $6(3.8)$ & 0.343 & $6(6.7)$ & $2(2.2)$ & 0.148 \\
\hline Diarrhea & $4(4.3)$ & $5(3.2)$ & 0.642 & $4(4.4)$ & $3(3.3)$ & 0.700 \\
\hline
\end{tabular}

Abbreviations: PSM, propensity score matching; DOS, docetaxel, oxaliplatin and S-I; SOX, oxaliplatin and S-I; NA, not available; NAC, neoadjuvant chemotherapy.

Table 4 Surgical Resection Rate for All Patients Receiving NAC

\begin{tabular}{|c|c|c|c|c|c|c|}
\hline \multirow[t]{2}{*}{ Variable } & \multicolumn{3}{|c|}{ Before PSM } & \multicolumn{3}{|c|}{ After PSM } \\
\hline & $\begin{array}{l}\text { DOS } \\
n=92 \text { (\%) }\end{array}$ & $\begin{array}{l}\text { sox } \\
n=156(\%)\end{array}$ & $\mathbf{P}$ & $\begin{array}{l}\text { DOS } \\
n=90 \text { (\%) }\end{array}$ & $\begin{array}{l}\text { sox } \\
\text { n=90 (\%) }\end{array}$ & $\mathbf{P}$ \\
\hline $\begin{array}{l}\text { Radical surgery } \\
\text { Yes } \\
\text { No }\end{array}$ & $\begin{array}{l}77(83.7) \\
15(16.3)\end{array}$ & $\begin{array}{l}126(80.8) \\
30(19.2)\end{array}$ & 0.564 & $\begin{array}{l}75(83.3) \\
15(16.7)\end{array}$ & $\begin{array}{l}62(68.9) \\
28(31.1)\end{array}$ & 0.023 \\
\hline $\begin{array}{l}\text { R0 resection } \\
\text { Yes } \\
\text { No }\end{array}$ & $\begin{array}{l}74(80.4) \\
18(19.6)\end{array}$ & $\begin{array}{l}|2|(77.6) \\
35(22.4)\end{array}$ & 0.594 & $\begin{array}{l}72(80.0) \\
18(20.0)\end{array}$ & $\begin{array}{l}58(64.4) \\
32(35.6)\end{array}$ & 0.020 \\
\hline $\begin{array}{l}\text { Residual tumor classification } \\
\text { R0 } \\
\text { RI } \\
\text { R2 } \\
\text { No surgery }\end{array}$ & $\begin{array}{l}74(80.4) \\
2(2.2) \\
1(1.1) \\
15(16.3)\end{array}$ & $\begin{array}{l}12 \mid(77.6) \\
3(1.9) \\
2(1.3) \\
30(19.2)\end{array}$ & 0.946 & $\begin{array}{l}72(80.0) \\
2(2.2) \\
1(1.1) \\
15(16.7)\end{array}$ & $\begin{array}{l}58(64.4) \\
2(2.2) \\
2(2.2) \\
28(31.1)\end{array}$ & 0.123 \\
\hline
\end{tabular}

Abbreviations: PSM, propensity score matching; DOS, docetaxel, oxaliplatin and S-I; SOX, oxaliplatin and S-I; NAC, neoadjuvant chemotherapy.

than the SOX arm ( $\mathrm{p}=0.003$ ) (Figure 2B). Accordingly, the median survival time for patients in DOS group and SOX group was 62 months and 41 months, respectively. The 3 -year survival rate in DOS group and SOX group was $63.1 \%$ and $55.1 \%$, respectively $(\mathrm{p}=0.288$ ); the 5 -year survival rate was $51.6 \%$ and $25.8 \%$, respectively $(\mathrm{p}<0.001)$.

\section{Univariate and Multivariate Analyses of Prognostic Factors}

As shown in Table 6, univariate analysis indicated that the NAC regimen, tumor differentiation, cTNM stage, Lauren classification, R0 resection rate, TLND, and NAC response were potential prognostic factors based on the PSM dataset. Multivariate analysis showed that the NAC regimen, cTNM stage, and R0 resection rate were independent prognostic factors. Patients receiving DOS NAC were associated with significant survival benefits as compared with those receiving the SOX regimen (HR, 1.905; 95\% CI, 1.099-3.303, $\mathrm{p}=0.022$ ). Besides, the worse overall survival was observed in patients with TLND less than 16 based on either unmatched $(\mathrm{p}=0.003$, Figure $2 \mathrm{C}$ ) or PSM ( $\mathrm{p}=0.022$, Figure 2D) population.

\section{Subgroup Analysis}

Subgroup analysis was performed in the PSM population. No statistically significant interaction effect with the NAC regimen on survival was observed across all subgroups examined. However, variations were still detected between 
Table 5 Surgical Outcomes and Post-Operative Pathology

\begin{tabular}{|c|c|c|c|c|c|c|}
\hline \multirow[t]{2}{*}{ Variable } & \multicolumn{3}{|c|}{ Before PSM } & \multicolumn{3}{|c|}{ After PSM } \\
\hline & $\begin{array}{l}\text { DOS } \\
n=77(\%)\end{array}$ & $\begin{array}{l}\text { sox } \\
n=126(\%)\end{array}$ & $\mathbf{P}$ & $\begin{array}{l}\text { DOS } \\
n=75 \text { (\%) }\end{array}$ & $\begin{array}{l}\text { sox } \\
n=62(\%)\end{array}$ & $\mathbf{P}$ \\
\hline Complications & $9(11.7)$ & 14 (II.I) & 0.9 & $9(12.0)$ & $9(14.5)$ & 0.664 \\
\hline Perioperative mortality & $0(0)$ & $0(0)$ & NA & $0(0)$ & $0(0)$ & NA \\
\hline TLN dissected & $25.4 \pm 7.0$ & $25.1 \pm 6.4$ & 0.763 & $25.3 \pm 7.1$ & $25.3 \pm 6.5$ & 0.976 \\
\hline урТ staging & & & 0.078 & & & 0.043 \\
\hline урТ0 & $6(7.8)$ & $4(3.2)$ & & $6(8.0)$ & $2(3.2)$ & \\
\hline урТІ & $22(28.6)$ & $20(15.9)$ & & $22(29.3)$ & $10(16.1)$ & \\
\hline урT2 & $26(33.8)$ & $47(37.3)$ & & $25(33.3)$ & I7 (27.4) & \\
\hline урТ3 & $15(16.3)$ & $34(27.0)$ & & $14(18.7)$ & $17(27.4)$ & \\
\hline урТ4a & $8(10.4)$ & $21(16.7)$ & & $8(10.7)$ & $16(25.8)$ & \\
\hline ypN staging & & & 0.187 & & & 0.143 \\
\hline ypNO & $39(50.6)$ & $45(35.7)$ & & $38(50.7)$ & $20(32.3)$ & \\
\hline ypNI & $22(28.6)$ & $52(4 I .3)$ & & $22(29.3)$ & $21(33.9)$ & \\
\hline ypN2 & $9(11.7)$ & $16(12.7)$ & & $8(10.6)$ & II (I7.7) & \\
\hline ypN3 & $7(9.1)$ & $13(10.3)$ & & $7(9.3)$ & $10(16.1)$ & \\
\hline
\end{tabular}

Abbreviations: PSM, propensity score matching; DOS, docetaxel, oxaliplatin and S-I; SOX, oxaliplatin and S-I; TLN, total lymph node; NA, not available; NAC, neoadjuvant chemotherapy.

strata in some variables (Figure 3). Male and middle-aged (40 59 years) were the demographic characteristics that predict a survival benefit from the DOS regimen compared with the SOX regimen. Besides, patients with welldifferentiated tumors and intestinal Lauren classification were more likely to benefit from DOS as compared with SOX. In addition, patients benefited from the addition of docetaxel regardless of the clinical $\mathrm{T}$ stage, but those with high clinical N stage (N2-3) did not.

\section{Discussion}

Radical resection combined with D2 lymphadenectomy has currently been widely accepted as the standard treatment for LAGC. $^{24-26}$ However, tumor recurrence and metastasis are usually inevitable in most patients, and OS in patients with advanced GC remains poor. ${ }^{27}$ To further improve the survival, adjuvant chemotherapy, perioperative chemotherapy, and adjuvant chemoradiation have been recommended in Asia, ${ }^{28}$ Europe, ${ }^{29}$ and the USA, ${ }^{30}$ respectively. In particular, NAC is a reasonable option for patients with more locally advanced disease who may be at risk of a positive resection margin under upfront surgery. ${ }^{31}$ The present study indicated that DOS was superior to SOX in terms of chemotherapy response, radical resection rate, $\mathrm{R} 0$ resection rate, and $\mathrm{OS}$. Both NAC regimens were generally well tolerated, although a relatively higher overall chemotherapy-related toxicity, especially leukopenia and neutropenia, were observed in DOS group.

The potential benefit of NAC includes the early elimination of micrometastases to improve survival. ${ }^{32}$ More importantly, NAC could help downstage the tumor, which in turn aids in performing R0 resection in patients with potentially unresectable GC who would have been otherwise excluded from attempts at curative resection. ${ }^{33}$ This is especially important for patients with locally advanced large, bulky tumors or metastatic lymph nodes that are not amenable to curative resection at presentation. ${ }^{9}$ As reported in previous studies, the prognosis for LAGC with extensive lymph node metastasis, or bulky lymph nodes along the celiac, splenic, common hepatic, or proper hepatic arteries, remains poor even though curative resection is achieved. ${ }^{34}$ Therefore, in the past decades, several practice-changing clinical trials compared NAC with surgery alone and confirmed the survival benefit of NAC for LAGC. ${ }^{12,13}$ However, very few head-to-head studies have focused on direct comparison of different NAC regimens for LAGC, resulting in the diversity of recommendations that exists within the published studies and the NCCN guidelines. $^{16}$

The landmark study on docetaxel, cisplatin, and fluorouracil (DCF) is the V325 trial, ${ }^{35}$ which showed the superiority of triplet chemotherapy with DCF over doublet chemotherapy with cisplatin plus fluorouracil (CF) as 

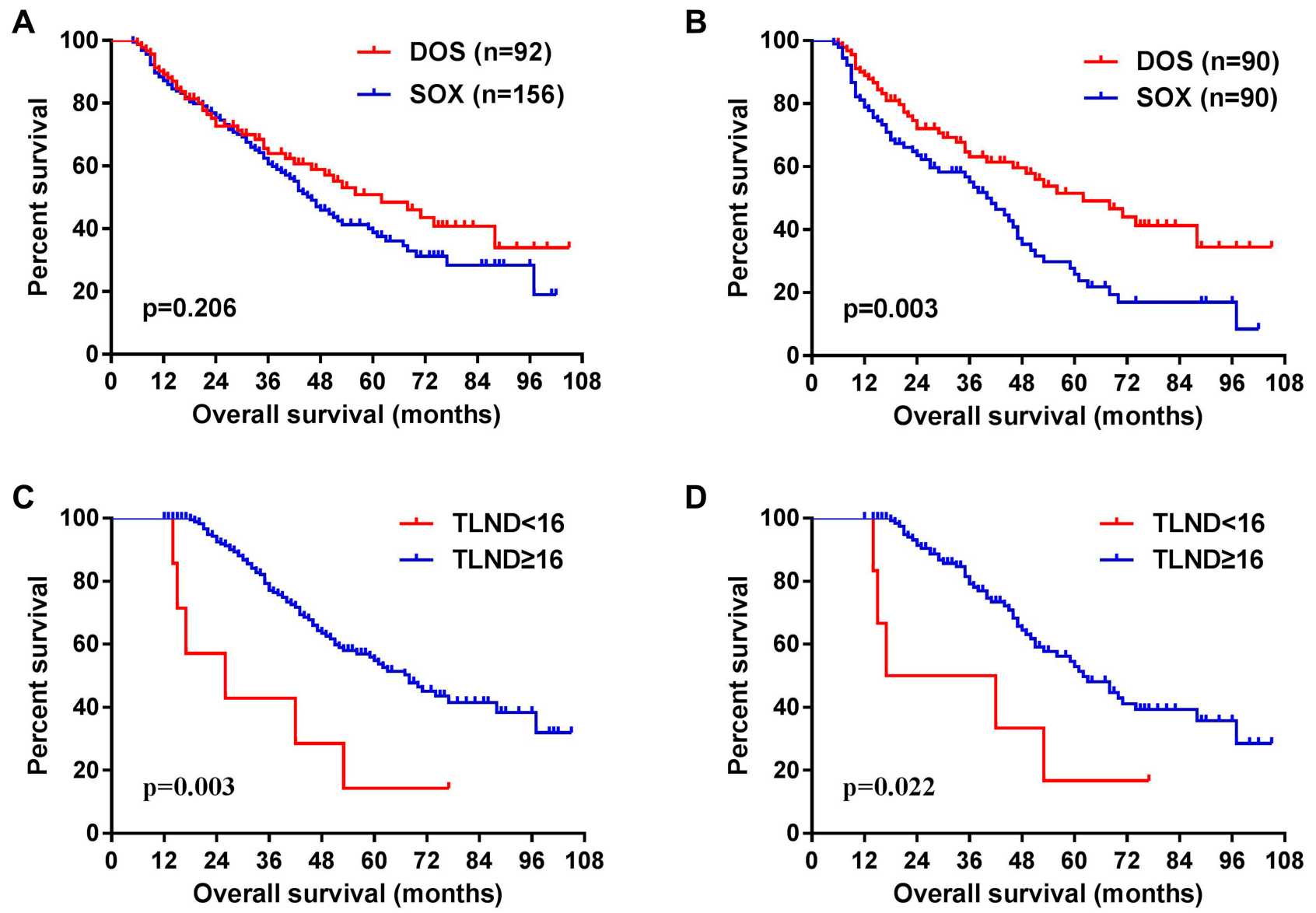

Figure 2 Kaplan-Meier overall survival analysis. (A) DOS group $(n=92)$ vs SOX group $(n=156)$ before PSM. (B) DOS group ( $n=90)$ vs SOX group ( $n=90)$ after PSM. (C) TLND $<16$ vs TLND $\geq 16$ before PSM. (D) TLND $<16$ vs TLND $\geq 16$ after PSM.

Abbreviations: DOS, docetaxel, oxaliplatin and S-I; SOX, oxaliplatin and S-I; TLND, total lymph node dissection.

a palliative therapy for patients with advanced GC. Evidence was also obtained in support of the modified DCF (mDCF) regimens with the substitution of oral 5-FU prodrugs for continuous infusion of 5-FU or the substitution of oxaliplatin for cisplatin. ${ }^{36-38}$ Moreover, $\mathrm{DCF} / \mathrm{mDCF}$ was investigated as a NAC for GC in an attempt to enhance the resection rate, which finally resulted in improved survival. ${ }^{39-41}$ More importantly, encouraging results were witnessed in some unresectable highly advanced GC patients who obtained conversion gastrectomy following the NAC with DCF/DCS. ${ }^{42,43}$ The FLOT4-AIO trial is the only prospective randomized head-to-head trial to compare two different NAC regimens for LAGC, ${ }^{29}$ which showed that the FLOT regimen was associated with a better pathological response, a higher R0 resection rate, a lower post-operative pathological stage ${ }^{29}$ and better OS than the ECF regimen, ${ }^{14}$ indicating that docetaxel is an optimal surrogate for epirubicin as a component of NAC for LAGC. Collectively, these results are consistent with the present study to favor the use of DOS as a NAC for LAGC.

In contrast, two recently released Japanese studies have come to the opposite conclusion. Okabe et $\mathrm{al}^{44}$ reported that induction chemotherapy with DCS failed to show superiority to CS (cisplatin plus S-1) in advanced GC patients with peritoneal metastasis. Also, the JCOG1002 study explored the efficacy and safety of adding docetaxel (DCS) to the standard CS NAC therapy for LAGC with bulky lymph node and/or para-aortic lymph node metastasis. The clinical RR was $57.7 \%$, and R0 resection was achieved in $84.6 \%$ patients. ${ }^{45}$ The 5 -year OS and relapsefree survival (RFS) was $54.9 \%$ and $47.7 \%$, respectively. ${ }^{46}$ However, considering the excellent results from JCOG0405 with CS, ${ }^{47}$ the author believed that DCS had no superiority to the traditional CS protocol in either shortterm outcomes or long-term survival. Since only $40 \mathrm{mg} / \mathrm{m}^{2}$ dose of docetaxel was given in a four-week cycle in the above two studies, the varied scheme and dosage may 
Table 6 Predictors of Mortality in PSM Analysis $(n=180)$

\begin{tabular}{|c|c|c|c|c|c|c|}
\hline \multirow[t]{2}{*}{ Variable } & \multicolumn{3}{|c|}{ Univariate Analysis } & \multicolumn{3}{|c|}{ Multivariate Analysis } \\
\hline & HR & $95 \% \mathrm{Cl}$ & $\mathbf{P}$ & HR & $95 \% \mathrm{Cl}$ & $\mathbf{P}$ \\
\hline NAC regimen & & & 0.004 & & & 0.022 \\
\hline DOS & Ref & & & Ref & & \\
\hline sox & 1.796 & $1.203-2.68 \mid$ & & 1.905 & $1.099-3.303$ & \\
\hline Gender & & & 0.067 & & & \\
\hline Male & Ref & & & & & \\
\hline Female & 0.663 & $0.427-1.029$ & & & & \\
\hline Age (years) & & & 0.175 & & & \\
\hline$<40$ & Ref & $0.391-1.159$ & & & & \\
\hline $4 I-59$ & 0.673 & & & & & \\
\hline $60-75$ & 0.982 & $0.573-1.683$ & & & & \\
\hline Tumor location & & & 0.198 & & & \\
\hline Upper & Ref & & & & & \\
\hline Middle & 1.589 & $0.954-2.648$ & & & & \\
\hline Lower & 1.286 & $0.749-2.208$ & & & & \\
\hline Differentiation & & & 0.015 & & & \\
\hline Well & Ref & & & & & \\
\hline Moderately & 1.132 & $0.523-2.447$ & & & & \\
\hline Poorly & 2.035 & $1.013-4.089$ & & & & \\
\hline cTNM staging & & & $<0.001$ & & & $<0.001$ \\
\hline II & Ref & & & Ref & & \\
\hline III & 9.848 & $6.030-16.085$ & & 8.912 & $4.897-16.217$ & \\
\hline Lauren classification & & & 0.017 & & & \\
\hline Intestinal & Ref & & & & & \\
\hline Diffuse & 1.775 & $1.126-2.798$ & & & & \\
\hline Mixed & 1.94 & $1.143-3.293$ & & & & \\
\hline RO resection & 81.367 & $33.982-194.831$ & $<0.001$ & 27.168 & $7.310-100.972$ & $<0.001$ \\
\hline TLND & & & 0.029 & & & \\
\hline$<16$ & Ref & & & & & \\
\hline$\geq 16$ & 0.359 & $0.143-0.902$ & & & & \\
\hline Complication & $\mathrm{I} .74 \mathrm{I}$ & $0.629-4.815$ & 0.286 & & & \\
\hline NAC response & & & $<0.001$ & & & \\
\hline CR & 0.036 & $0.009-0.152$ & & & & \\
\hline PR & 0.113 & $0.072-0.180$ & & & & \\
\hline SD & Ref & & & & & \\
\hline PD & 1.815 & $0.977-3.374$ & & & & \\
\hline NAC toxicity & I.I72 & $0.788-1.743$ & 0.434 & & & \\
\hline
\end{tabular}

Abbreviations: PSM, propensity score matching; DOS, docetaxel, oxaliplatin and S-I; SOX, oxaliplatin and S-I; NAC, neoadjuvant chemotherapy; TLND, total lymph node dissected; CR, complete response; PR, partial response; SD, stable disease; PD, progression disease; HR, hazard ratio; Ref, reference.

partially explain the discrepancies between the studies. Therefore, a high dose of docetaxel is usually needed in the neoadjuvant setting, since patients can tolerate more intense regimens and neoadjuvant treatment should have strong efficacy to maximize tumor shrinkage and prevent disease progression before surgery.
In our opinion, whether the addition of docetaxel to SOX can obtain survival benefit depends on multiple factors, including gender, age, tumor differentiation, Lauren classification, and the clinical stage, as is shown in the present study. Additionally, as R0 resection is an independent prognostic factor in our multivariate regression 


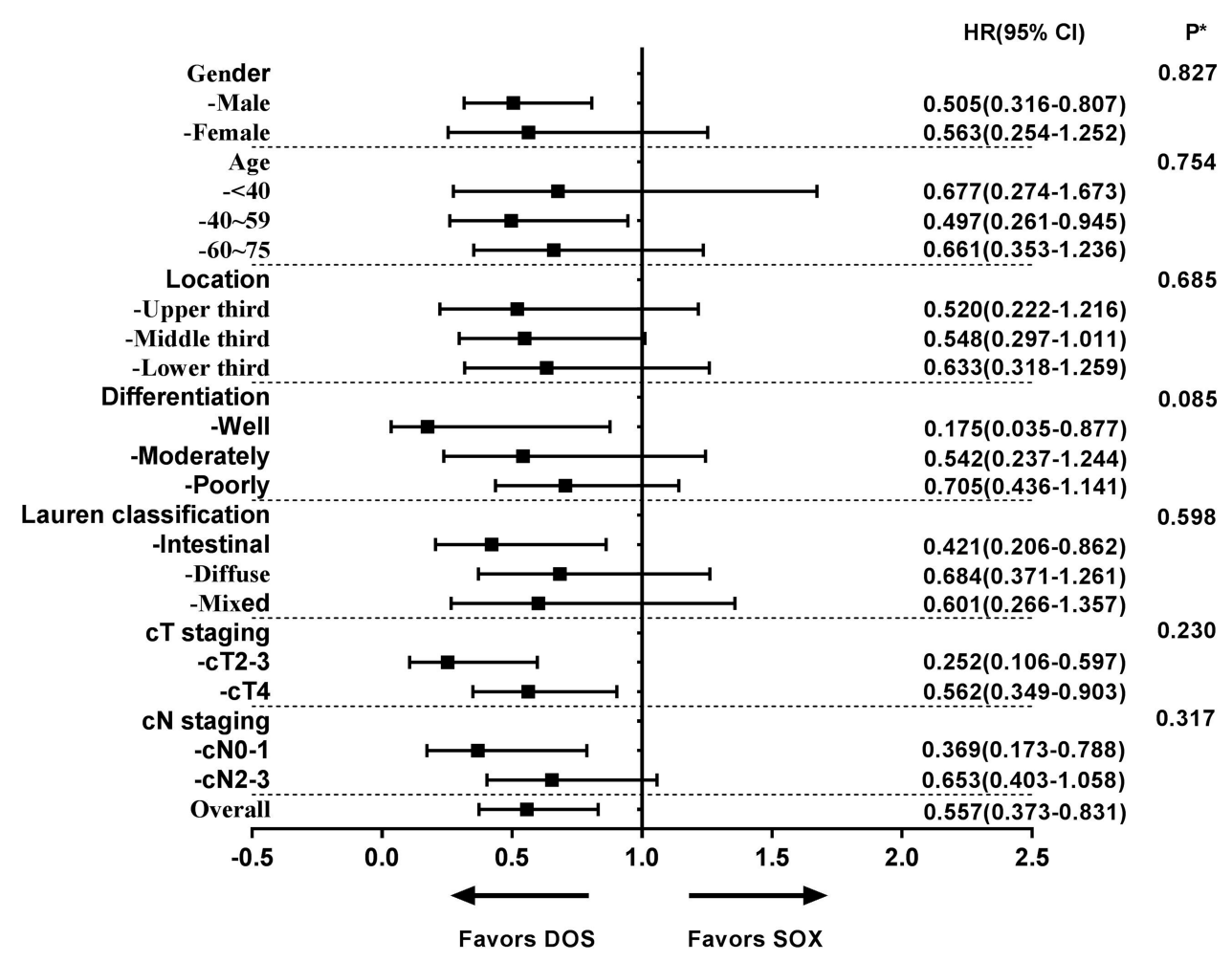

Figure 3 Subgroup analysis in the propensity score matched analysis. *p refers to $p$ value for interaction analysis.

Abbreviations: DOS, docetaxel, oxaliplatin and S-I; SOX, oxaliplatin and S-I.

analysis, DOS could probably prolong the survival, at least partially, by increasing the R0 resection. This is a possible explanation for the fact that DOS did not show superiority to SOX in the palliative treatment setting. Theoretically, docetaxel is effective in restraining the locally primary tumor due to its easy transition into the peritoneal cavity and high affinity for the peritoneum. ${ }^{48}$ According to our practice experience, many patients showed fibrous change of the previous serosal invasion sites after NAC with no evidence of serosal invasion on postoperative pathological examination. In this circumstance, the dissemination caused by surgical manipulation would be effectively avoided. This may explain the results from our subgroup analysis that patients benefited from the addition of docetaxel regardless of the clinical $\mathrm{T}$ stage. On the contrary, the SOX regimen is believed to be effective enough for Chinese patients in controlling lymph node metastasis, ${ }^{49}$ and there would be no extra benefit from the addition of docetaxel to the SOX regimen. Therefore, DOS did not show superiority to SOX as NAC when extensive lymph nodes were present, as is shown in the subgroup analysis from our study that patients with high clinical $\mathrm{N}$ stages (N2-3) did not obtain a benefit based on comparative analysis. Considering the $\mathrm{p}$ value was close to 0.05 in the statistical analysis, this finding should be interpreted with caution.

The consensus surrounding the extent of lymphadenectomy has been reached that D2 resection with TLND of at least 15 should be the standard for upfront radical surgery. ${ }^{16,50}$ However, the debate has been ongoing for the optimal lymphadenectomy strategy in the neoadjuvant therapy setting. An exploratory study of the optimal degree of lymph node dissection for LAGC after neoadjuvant chemoradiation showed that patients with D2 resection and TLND of 15 or more have better survival compared with those with D1 and TLND of fewer than $15 .^{51}$ This is consistent with the results from our present study that OS was worse within the whole NAC population with TLND less than 16. In addition, the existence of residual tumor in LNs, rather than regression change in LNs, is meaningful for predicting the prognosis after NAC in GC patients. ${ }^{52}$ Therefore, despite the potential effects of tumor downstaging with perioperative therapy, a thorough logoregional lymphatic resection is still recommended. As a high volume center of GC, surgeons in our department are really proficient in performing the D2 radical gastrectomy with extensive lymphadenectomy, and the incidence of surgical complications was 
very low. This may partially explain the excellent OS in our data.

The $\mathrm{DCF} / \mathrm{mDCF}$ regimen can be administered with varied drug dosage and cycle scheme. Comparatively, the dose intensity of docetaxel given in patients from Japan is higher than that in patients from Europe. ${ }^{29,53}$ A dosefinding study indicated that the recommended dose of the DOS regimen in patients with GC was docetaxel $52.5 \mathrm{mg} /$ $\mathrm{m}^{2}$ and oxaliplatin $105 \mathrm{mg} / \mathrm{m}^{2}$ on day 1 and $\mathrm{S}-180 \mathrm{mg} / \mathrm{m}^{2}$ on day 1-14 of an every 21-day cycle. ${ }^{54}$ In the present study, we showed that the 3-week NAC regimen with docetaxel $75 \mathrm{mg} / \mathrm{m}^{2}$, oxaliplatin $130 \mathrm{mg} / \mathrm{m}^{2}$, and $\mathrm{S}-1$ $80 \mathrm{mg} / \mathrm{m}^{2}$ was well tolerated among the Chinese patients, although an increase in toxicity was observed. Actually, these disadvantages are well counterbalanced by the good response and survival benefit.

Some limitations of this study need to be illustrated. Firstly, SOX group included more patients deemed unfit (higher age) or unnecessary (less advanced tumor staging) for intensive chemotherapy than the DOS group, which resulted in a certain imbalance in the baseline characteristics between the two groups. Thus, we performed a PSM analysis to minimize the selection bias. Knowing that a retrospective study is underpowered, a prospective randomized trial is warranted to draw a firmer conclusion in future. Secondly, the patients included in this study are all Chinese, and most of them are resided in the coastal area of East China and Jiangxi Province. Therefore, the generalizability of the findings to population with different races, ethnics, or geographical environments may be limited. Finally, all surgical procedures in this study were performed by three senior surgeons (Q.C., W.W., and R. Y.) in a single center. Each of them has performed more than 1000 gastrectomy procedures in total as the head surgeon and has an annual gastrectomy volume of approximately 100 . Therefore, it is not clear whether the conclusions can be extended to other surgeons with different levels of surgical experience.

In conclusion, DOS is superior to SOX as a NAC regimen in terms of tumor response, $\mathrm{R} 0$ resection rate and $\mathrm{OS}$ in patients with LAGC. Therefore, NAC with DOS is safe and feasible which is worth popularizing in clinical practice.

\section{Statement of Ethics}

This study was conducted in accordance with the Declaration of Helsinki and approved by the ethics committee of Changzheng Hospital, Second Military Medical University.

\section{Acknowledgments}

We wish to thank staff members from the Biobank of Shanghai Changzheng Hospital who participated in this study.

\section{Author Contributions}

All authors made substantial contributions to conception and design, acquisition of data, or analysis and interpretation of data; took part in drafting the article or revising it critically for important intellectual content; gave final approval of the version to be published; and agree to be accountable for all aspects of the work.

\section{Funding}

This study was supported by grants from the National Natural Science Foundation of China (81773049, 81602617), the Program for Excellent Young Specialist training of Shanghai, China (2017), and the "Pyramid talent project" of Changzheng Hospital, Shanghai, China.

\section{Disclosure}

The authors declare no conflicts of interest.

\section{References}

1. Bray F, Ferlay J, Soerjomataram I, Siegel RL, Torre LA, Jemal A. Global cancer statistics 2018: GLOBOCAN estimates of incidence and mortality worldwide for 36 cancers in 185 countries. CA Cancer J Clin. 2018;68(6):394-424. doi:10.3322/caac.21492

2. Shen M, Xia R, Luo Z, et al. The long-term population impact of endoscopic screening programmes on disease burdens of gastric cancer in China: a mathematical modelling study. $J$ Theor Biol. 2019;484:109996. doi:10.1016/j.jtbi.2019.109996

3. Gonzalez CA, Agudo A. Carcinogenesis, prevention and early detection of gastric cancer: where we are and where we should go. Int $J$ Cancer. 2012;130(4):745-753. doi:10.1002/ijc.26430

4. Zhang X, Li M, Chen S, et al. Endoscopic screening in asian countries is associated with reduced gastric cancer mortality: a meta-analysis and systematic review. Gastroenterology. 2018;155(2):347-354 e349. doi:10.1053/j.gastro.2018.04.026

5. Chen W, Zheng R, Baade PD, et al. Cancer statistics in China, 2015. CA Cancer J Clin. 2016;66(2):115-132. doi:10.3322/caac.21338

6. Van Cutsem E, Sagaert X, Topal B, Haustermans K, Prenen H. Gastric cancer. Lancet. 2016;388(10060):2654-2664. doi:10.1016/S01406736(16)30354-3

7. Wu L, Ge L, Qin Y, et al. Postoperative morbidity and mortality after neoadjuvant chemotherapy versus upfront surgery for locally advanced gastric cancer: a propensity score matching analysis. Cancer Manag Res. 2019;11:6011-6018. doi:10.2147/CMAR.S203880

8. Xiong BH, Cheng Y, Ma L, Zhang CQ. An updated meta-analysis of randomized controlled trial assessing the effect of neoadjuvant chemotherapy in advanced gastric cancer. Cancer Invest. 2014;32 (6):272-284. doi:10.3109/07357907.2014.911877 
9. Cascinu S, Scartozzi M, Labianca R, et al. High curative resection rate with weekly cisplatin, 5-fluorouracil, epidoxorubicin, 6S-leucovorin, glutathione, and filgastrim in patients with locally advanced, unresectable gastric cancer: a report from the Italian group for the study of digestive tract cancer (GISCAD). $\mathrm{Br}$ $J$ Cancer. 2004;90(8):1521-1525. doi:10.1038/sj.bjc.6601752

10. Oki E, Emi Y, Kusumoto T, et al. Phase II study of docetaxel and S-1 (DS) as neoadjuvant chemotherapy for clinical stage III resectable gastric cancer. Ann Surg Oncol. 2014;21(7):2340-2346. doi:10.1245/ s10434-014-3594-9

11. Schuhmacher C, Gretschel S, Lordick F, et al. Neoadjuvant chemotherapy compared with surgery alone for locally advanced cancer of the stomach and cardia: European organisation for research and treatment of cancer randomized trial 40954. J Clin Oncol. 2010;28 (35):5210-5218. doi:10.1200/JCO.2009.26.6114

12. Cunningham D, Allum WH, Stenning SP, et al. Perioperative chemotherapy versus surgery alone for resectable gastroesophageal cancer. $N$ Engl J Med. 2006;355(1):11-20. doi:10.1056/ NEJMoa055531

13. Ychou M, Boige V, Pignon JP, et al. Perioperative chemotherapy compared with surgery alone for resectable gastroesophageal adenocarcinoma: an FNCLCC and FFCD multicenter Phase III trial. $J$ Clin Oncol. 2011;29(13):1715-1721. doi:10.1200/JCO.2010.33.0597

14. Al-Batran SE, Hofheinz RD, Pauligk C, et al. Histopathological regression after neoadjuvant docetaxel, oxaliplatin, fluorouracil, and leucovorin versus epirubicin, cisplatin, and fluorouracil or capecitabine in patients with resectable gastric or gastro-oesophageal junction adenocarcinoma (FLOT4-AIO): results from the Phase 2 part of a multicentre, open-label, randomised phase 2/3 trial. Lancet Oncol. 2016;17(12):1697-1708. doi:10.1016/S1470-2045(16)30531-9

15. Wang X, Zhao L, Liu H, et al. A phase II study of a modified FOLFOX6 regimen as neoadjuvant chemotherapy for locally advanced gastric cancer. $B r J$ Cancer. 2016;114(12):1326-1333. doi:10.1038/bjc. 2016.126

16. National comprehensive cancer network clinical practice guidelines in oncology: gastric cancer. Version 2; 2019. Available from: https:// www.nccn.org/. Accessed July 9, 2020.

17. Koizumi W, Narahara H, Hara T, et al. S-1 plus cisplatin versus S-1 alone for first-line treatment of advanced gastric cancer (SPIRITS trial): a phase III trial. Lancet Oncol. 2008;9(3):215-221. doi:10.1016/S1470-2045(08)70035-4

18. Yoshikawa T, Muro K, Shitara K, et al. Effect of first-line S-1 plus oxaliplatin with or without ramucirumab followed by paclitaxel plus ramucirumab on advanced gastric cancer in east asia: the phase 2 RAINSTORM randomized clinical trial. JAMA Netw Open. 2019;2 (8):e198243. doi:10.1001/jamanetworkopen.2019.8243

19. Nakamura Y, Yamanaka T, Chin K, et al. Survival outcomes of two phase 2 studies of adjuvant chemotherapy with S-1 plus oxaliplatin or capecitabine plus oxaliplatin for patients with gastric cancer after D2 gastrectomy. Ann Surg Oncol. 2019;26(2):465-472. doi:10.1245/ s10434-018-7063-8

20. Dahdaleh FS, Turaga KK. Evolving treatment strategies and outcomes in advanced gastric cancer with peritoneal metastasis. Surg Oncol Clin N Am. 2018;27(3):519-537. doi:10.1016/j. soc.2018.02.006

21. Tamegai H, Kaiga T, Kochi M, et al. Pharmacokinetics of docetaxel in gastric cancer patients with malignant ascites. Cancer Chemother Pharmacol. 2013;71(3):727-731. doi:10.1007/s00280-012-2066-9

22. Eisenhauer EA, Therasse P, Bogaerts J, et al. New response evaluation criteria in solid tumours: revised RECIST guideline (version 1.1). Eur $J$ Cancer. 2009;45(2):228-247. doi:10.1016/j. ejca.2008.10.026

23. Trotti A, Colevas AD, Setser A, et al. CTCAE v3.0: development of a comprehensive grading system for the adverse effects of cancer treatment. Semin Radiat Oncol. 2003;13(3):176-181. doi:10.1016/ S1053-4296(03)00031-6
24. Japanese Gastric Cancer A. Japanese gastric cancer treatment guidelines 2014 (ver. 4). Gastric Cancer. 2017;20(1):1-19. doi:10.1007/ s10120-016-0622-4

25. Okines A, Verheij M, Allum W, Cunningham D, Cervantes A, Group EGW. Gastric cancer: ESMO clinical practice guidelines for diagnosis, treatment and follow-up. Ann Oncol. 2010;21(Suppl 5): v50-54. doi:10.1093/annonc/mdq164

26. Ajani JA, Bentrem DJ, Besh S, et al. Gastric cancer, version 2.2013: featured updates to the NCCN guidelines. J Natl Compr Canc Netw. 2013;11(5):531-546. doi:10.6004/jncen.2013.0070

27. Montagnani F, Crivelli F, Aprile G, et al. Long-term survival after liver metastasectomy in gastric cancer: systematic review and meta-analysis of prognostic factors. Cancer Treat Rev. 2018;69:11-20. doi:10.1016/j.ctrv.2018.05.010

28. Noh SH, Park SR, Yang HK, et al. Adjuvant capecitabine plus oxaliplatin for gastric cancer after D2 gastrectomy (CLASSIC): 5-year follow-up of an open-label, randomised Phase 3 trial. Lancet Oncol. 2014;15(12):1389-1396. doi:10.1016/S1470-2045(14)70473-5

29. Al-Batran SE, Homann N, Pauligk C, et al. Perioperative chemotherapy with fluorouracil plus leucovorin, oxaliplatin, and docetaxel versus fluorouracil or capecitabine plus cisplatin and epirubicin for locally advanced, resectable gastric or gastro-oesophageal junction adenocarcinoma (FLOT4): a randomised, phase 2/3 trial. Lancet. 2019;393(10184):1948-1957. doi:10.1016/S0140-6736(18)32557-1

30. Smalley SR, Benedetti JK, Haller DG, et al. Updated analysis of SWOG-directed intergroup study 0116: a phase III trial of adjuvant radiochemotherapy versus observation after curative gastric cancer resection. J Clin Oncol. 2012;30(19):2327-2333. doi:10.1200/ JCO.2011.36.7136

31. Smyth EC, Cunningham D. Gastric cancer in 2012: defining treatment standards and novel insights into disease biology. Nat Rev Clin Oncol. 2013;10(2):73-74. doi:10.1038/nrclinonc.2012.228

32. Kim IH. Current status of adjuvant chemotherapy for gastric cancer. World J Gastrointest Oncol. 2019;11(9):679-685. doi:10.4251/wjgo. v11.i9.679

33. Yano $M$, Shiozaki $H$, Inoue $M$, et al. Neoadjuvant chemotherapy followed by salvage surgery: effect on survival of patients with primary noncurative gastric cancer. World $J$ Surg. 2002;26 (9):1155-1159. doi:10.1007/s00268-002-6362-0

34. Park IH, Kim SY, Kim YW, et al. Clinical characteristics and treatment outcomes of gastric cancer patients with isolated para-aortic lymph node involvement. Cancer Chemother Pharmacol. 2011;67 (1):127-136. doi:10.1007/s00280-010-1296-y

35. Van Cutsem E, Moiseyenko VM, Tjulandin S, et al. Phase III study of docetaxel and cisplatin plus fluorouracil compared with cisplatin and fluorouracil as first-line therapy for advanced gastric cancer: a report of the V325 study group. J Clin Oncol. 2006;24(31):4991-4997. doi:10.1200/JCO.2006.06.8429

36. Zhang F, Zhang Y, Jia Z, Wu H, Gu K. Oxaliplatin-based regimen is superior to cisplatin-based regimen in tumour remission as first-line chemotherapy for advanced gastric cancer: a meta-analysis. $J$ Cancer. 2019;10(8):1923-1929. doi:10.7150/jca.28896

37. Chen XD, He FQ, Chen M, Tang LC, Tang XL. Can S-1 replace fluorouracil for advanced gastric cancer? A PRISMA-compliant systematic review and meta-analysis. Medicine (Baltimore). 2016;95 (24):e3916. doi:10.1097/MD.0000000000003916

38. Pernot S, Mitry E, Samalin E, et al. Biweekly docetaxel, fluorouracil, leucovorin, oxaliplatin (TEF) as first-line treatment for advanced gastric cancer and adenocarcinoma of the gastroesophageal junction: safety and efficacy in a multicenter cohort. Gastric Cancer. 2014;17 (2):341-347. doi:10.1007/s10120-013-0266-6

39. Hosoda K, Azuma M, Katada C, et al. A phase II study of neoadjuvant chemotherapy with docetaxel, cisplatin, and S-1, followed by gastrectomy with D2 lymph node dissection for high-risk advanced gastric cancer: results of the KDOG1001 trial. Gastric Cancer. 2019;22(3):598-606. doi:10.1007/s10120-018-0884-0 
40. Wang Y, Cheng X, Cui YH, et al. Efficacy after preoperative capecitabine and oxaliplatin (XELOX) versus docetaxel, oxaliplatin and S1 (DOS) in patients with locally advanced gastric adenocarcinoma: a propensity score matching analysis. BMC Cancer. 2018;18(1):702. doi:10.1186/s12885-018-4615-z

41. Oyama K, Fushida S, Kinoshita J, et al. Efficacy of pre-operative chemotherapy with docetaxel, cisplatin, and S-1 (DCS therapy) and curative resection for gastric cancer with pathologically positive para-aortic lymph nodes. J Surg Oncol. 2012;105(6):535-541. doi:10.1002/jso. 22125

42. Sato Y, Ohnuma H, Nobuoka T, et al. Conversion therapy for inoperable advanced gastric cancer patients by docetaxel, cisplatin, and S-1 (DCS) chemotherapy: a multi-institutional retrospective study. Gastric Cancer. 2017;20(3):517-526. doi:10.1007/s10120-016-0633-1

43. Kinoshita J, Fushida S, Tsukada T, et al. Efficacy of conversion gastrectomy following docetaxel, cisplatin, and S-1 therapy in potentially resectable stage IV gastric cancer. Eur J Surg Oncol. 2015;41 (10):1354-1360. doi:10.1016/j.ejso.2015.04.021

44. Okabe $\mathrm{H}$, Hata $\mathrm{H}$, Hosogi $\mathrm{H}$, et al. A phase 2 study of induction chemotherapy using docetaxel, cisplatin, and S-1 for gastric cancer with peritoneal metastasis (KUGC06). Ann Surg Oncol. 2019;26 (6):1779-1786. doi:10.1245/s10434-019-07229-7

45. Ito S, Sano T, Mizusawa J, et al. A phase II study of preoperative chemotherapy with docetaxel, cisplatin, and S-1 followed by gastrectomy with D2 plus para-aortic lymph node dissection for gastric cancer with extensive lymph node metastasis: JCOG1002. Gastric Cancer. 2017;20(2):322-331. doi:10.1007/s10120-016-0619-z

46. Takahari D, Ito S, Mizusawa J, et al. Long-term outcomes of preoperative docetaxel with cisplatin plus S-1 therapy for gastric cancer with extensive nodal metastasis (JCOG1002). Gastric Cancer. 2019.

47. Tsuburaya A, Mizusawa J, Tanaka Y, et al. Neoadjuvant chemotherapy with S-1 and cisplatin followed by D2 gastrectomy with para-aortic lymph node dissection for gastric cancer with extensive lymph node metastasis. Br J Surg. 2014;101(6):653-660. doi:10.10 02/bjs. 9484
48. Kobayashi M, Sakamoto J, Namikawa T, et al. Pharmacokinetic study of paclitaxel in malignant ascites from advanced gastric cancer patients. World J Gastroenterol. 2006;12(9):1412-1415. doi:10.37 48/wjg.v12.i9.1412

49. Dong S, Yu JR, Zhang Q, Liu XS. Neoadjuvant chemotherapy in controlling lymph node metastasis for locally advanced gastric cancer in a Chinese population. $J$ Chemother. 2016;28(1):59-64. doi:10.1179/1973947815Y.0000000028

50. Songun I, Putter H, Kranenbarg EM, Sasako M, van de Velde CJ. Surgical treatment of gastric cancer: 15-year follow-up results of the randomised nationwide Dutch D1D2 trial. Lancet Oncol. 2010;11 (5):439-449. doi:10.1016/S1470-2045(10)70070-X

51. Allen CJ, Vreeland TJ, Newhook TE, et al. Prognostic value of lymph node yield after neoadjuvant chemoradiation for gastric cancer. Ann Surg Oncol. 2019.

52. Zhu YL, Sun YK, Xue XM, Yue JY, Yang L, Xue LY. Unnecessity of lymph node regression evaluation for predicting gastric adenocarcinoma outcome after neoadjuvant chemotherapy. World J Gastrointest Oncol. 2019;11(1):48-58. doi:10.4251/wjgo.v11.i1.48

53. Yamada Y, Boku N, Mizusawa J, et al. Docetaxel plus cisplatin and S-1 versus cisplatin and S-1 in patients with advanced gastric cancer (JCOG1013): an open-label, phase 3, randomised controlled trial. Lancet Gastroenterol Hepatol. 2019;4(7):501-510. doi:10.1016/ S2468-1253(19)30083-4

54. Zang DY, Yang DH, Kim MJ, et al. Dose-finding study of docetaxel, oxaliplatin, and S-1 for patients with advanced gastric cancer. Cancer Chemother Pharmacol. 2009;64(5):877-883. doi:10.1007/s00280009-0936-6

\section{Publish your work in this journal}

Cancer Management and Research is an international, peer-reviewed open access journal focusing on cancer research and the optimal use of preventative and integrated treatment interventions to achieve improved outcomes, enhanced survival and quality of life for the cancer patient.
The manuscript management system is completely online and includes a very quick and fair peer-review system, which is all easy to use. Visit http://www.dovepress.com/testimonials.php to read real quotes from published authors. 